\title{
Correction to: Catalytic oxidation of hydrogen on platinum
}

\section{Thermochemical approach}

\author{
Boris V. L'vov ${ }^{1}$. Andrew K. Galwey ${ }^{2}$
}

Published online: 27 April 2020

(c) Akadémiai Kiadó, Budapest, Hungary 2020

\section{Correction to: J Therm Anal Calorim (2013) 112:815-822 https://doi.org/10.1007/s10973-012-2567-0}

Due to a fault (oversight) of the authors, L'vov BV, Galwey AK, Fig 1 of the article: 'Catalytic oxidation of hydrogen on platinum: thermochemical approach.' (2013) J Therm Anal Calorim 112: 815-822. https://doi.org/10.1007/s1097 3-012-2567-0 is accompanied by an oxidation scheme based on the complete atomization of $\mathrm{PtO}_{2}$, while the caption for Figure 1 and the main text of the article relate exclusively to the oxidation mechanism based on the primary reduction of $\mathrm{PtO}_{2}$ with hydrogen. A correct diagram of this mechanism is shown in Fig 1c in an article by the same authors in 'Toward a general theory of heterogeneous reactions: thermochemical approach' (2013) J Therm Anal Calorim. 113: 561-568. https://doi.org/10.1007/s10973-012-2754z and in their article: (2013) Interpretation of the kinetic compensation effect in heterogeneous reactions: thermochemical approach> in Int Rev Phys Chem 32: 515-557. https://doi. org/10.1080/144235X.2013.822109.

Publisher's Note Springer Nature remains neutral with regard to jurisdictional claims in published maps and institutional affiliations.

The original article can be found online at https://doi.org/10.1007/ s10973-012-2567-0.

Andrew K. Galwey

aandk.galwey@talktalk.net

1 Department of Physical Chemistry, St Petersburg State Polytechnic University, St Petersburg, Russia 195251

2 Department of Chemistry, Rhodes University, Grahamstown 6140, South Africa 